\title{
Clinical Outcomes Observed among Biopsy Proven Lupus Nephritis Patients Treated with Mycophenolate Mofetil as First-line Therapy
}

\author{
Homa Timlin ${ }^{1}$, Laurence Magder ${ }^{2}$, Michelle Petri ${ }^{1}$ \\ 1. Rheumatology, The Johns Hopkins University School of Medicine, Baltimore, USA 2. Epidemiology and \\ Public Health, University of Maryland School of Medicine
}

$\square$ Corresponding author: Homa Timlin, htimlin1@jhmi.edu

Disclosures can be found in Additional Information at the end of the article

\section{Abstract}

\section{Background and objective}

The rate of end-stage renal disease from lupus nephritis has not declined, in spite of recent advances in therapeutics, such as mycophenolate mofetil (MMF). To provide insight into rates of the clinical outcomes in current practice after biopsy-proven lupus nephritis, we used a prospective cohort of the patients with newly diagnosed lupus nephritis, treated with MMF and observed their outcomes.

\section{Method}

Twenty systemic lupus erythematosus (SLE) patients who began mycophenolate mofetil shortly after a biopsy-confirmed diagnosis of lupus nephritis were included in the analysis. There were five patients with class III, nine with class IV, four with class III-V, one with class IV-V and two with class V lupus nephritis. The initial dose of mycophenolate mofetil was $1000 \mathrm{mg}$ twice daily. If no improvement was observed, the dose was increased to $1500 \mathrm{mg}$ twice daily after one month. We estimated the survival function for the time until the urine protein/creatinine reached 0.50 grams or less, after starting MMF by using an approach that accommodated interval-censored data. We also evaluated the treatment response using five different sets of criteria for the response that have previously been used in the clinical trials. These included the Bristol Myers-Squibb (BMS), the American College of Rheumatology (ACR), the lupus nephritis assessment with rituximab (LUNAR ), the Aspreva Lupus Management Study (ALMS), and the Abatacept and Cyclophosphamide Combination Efficacy and Safety Study (ACCESS).

Received 11/10/2017

Review began 11/15/2017

Review ended 11/30/2017

Published 12/04/2017

CC Copyright 2017

Timlin et al. This is an open access article distributed under the terms of the Creative Commons Attribution License CC-BY 3.0., which permits unrestricted use, distribution, and reproduction in any medium, provided the original author and source are credited.

\section{Result}

We estimated that $52 \%$ of the SLE patients reached 0.50 grams of proteinuria within 51 days of starting mycophenolate mofetil (95\% confidence interval 29\%-74\%) and 77\% reached 0.50 grams or less within 260 days (95\% confidence interval 57\%-97\%). The probability of response at 90 and 180 days was 5\% and 33\% (the Bristol Myers-Squibb), 26\% and 57\% (the American College of Rheumatology), and $11 \%$ and $28 \%$ (the lupus nephritis assessment with rituximab, the Aspreva Lupus Management Study and the Abatacept and Cyclophosphamide Combination Efficacy and Safety Study).

\section{Conclusion}

The complete renal response ranged from $28 \%$ to $57 \%$ at six months in the routine clinical

\section{How to cite this article}

Timlin H, Magder L, Petri M (December 04, 2017) Clinical Outcomes Observed among Biopsy Proven Lupus Nephritis Patients Treated with Mycophenolate Mofetil as First-line Therapy. Cureus 9(12): e1907. DOI 10.7759/cureus.1907 
practice, mirroring the results in randomized clinical trials. Regardless of the response measures, the complete renal response was slow and, by most indices, reached in only a minority of the patients by the end of six months of the induction therapy. This indicates the urgent need for the faster and more effective lupus nephritis treatments.

Categories: Allergy/Immunology, Nephrology, Rheumatology

Keywords: proteinuria, urine protein creatinine ratio, esrd (end stage renal disease), mycophenolate mofetil, systemic lupus erythematosus, lupus nephritis, bms (bristol myers-squibb), alms (aspreva lupus management study), acr (american college of rheumatology), lunar (lupus nephritis assessment with rituximab)

\section{Introduction}

Lupus nephritis occurs in 50-60\% of the systemic lupus erythematosus (SLE) patients within 10 years after the diagnosis [1-4]. The aggressive immunosuppressive therapy has improved the prognosis of the SLE patients with renal disease, but 5-20\% still progress to end-stage renal disease within 10 years following the diagnosis of nephritis. The progression to renal failure in the patients with lupus nephritis is higher in the African-American patients [5]. There may also be a genetic basis for poor renal outcomes [6]. Tektonidou, et al. demonstrated a decreased risk of the end-stage renal disease (ESRD) between 1970 and 1990, followed by a plateau and then, possibly an increased risk in the recent years [7]. A socioeconomic gradient is apparent in the prevalence of lupus nephritis with increased prevalence in poorer geographic areas [8].

Proteinuria is a major predictor of the poorer renal outcomes and is a part of all outcome measures used in lupus nephritis clinic trials. The renal outcome data from the Euro-Lupus Nephritis Trial showed that the level of proteinuria at 12 months is the individual best predictor of long-term renal outcome in the patients with lupus nephritis [9]. Four recent lupus nephritis trials, however, have each used a different definition of complete renal response and none is equivalent to the published recommendations of the American College of Rheumatology [10].

In this report, we compared these renal outcome measures in the clinical practice to assess complete renal response after starting mycophenolate mofetil as initial therapy for class III, IV or $\mathrm{V}$ in the immunosuppressant naive patients with lupus nephritis. We used five outcome measures including the Bristol-Myers Squibb (BMS), the American College of Rheumatology (ACR ), the lupus nephritis assessment with rituximab (LUNAR), the Aspreva Lupus Management Study (ALMS), and the Abatacept and Cyclophosphamide Combination Efficacy and Safety Study (ACCESS).

\section{Materials And Methods}

\section{Patients included}

The Hopkins Lupus Cohort is a prospective cohort of the patients with lupus who have been seen at the Johns Hopkins University since 1987 by one provider. The patients from the Hopkins Lupus Center were included in this analysis if they had biopsy-proven lupus nephritis class III$\mathrm{V}$, proteinuria of more than 0.50 grams at the time of the biopsy and were treated with mycophenolate mofetil (MMF) as their first immunosuppressive shortly after the biopsy. The patients were excluded if they were on hemodialysis, peritoneal dialysis, the patients who had a kidney transplant or had previous exposure to immunosuppressants for lupus nephritis. The 20 patients met the American College of Rheumatology and Systemic Lupus International Collaborating Clinics classification criteria for the SLE. 


\section{Clinical information collected}

The baseline urine protein/creatinine was assessed prior to initiating mycophenolate mofetil and updated at the clinic visits, per protocol. The patients were scheduled to be seen monthly or quarterly depending on their clinical condition, however, the frequency of the actual visit varied.

\section{Mycophenolate mofetil protocol}

The initial dose of mycophenolate mofetil was $1000 \mathrm{mg}$ twice daily. If the patient experienced no improvement, the dose was increased to $1500 \mathrm{mg}$ twice daily after a month.

\section{Treatment response definitions}

Table 1 shows the criteria for the response based on previous studies. For the BMS outcome, the complete renal response required the urine protein/creatinine ratio to be $\leqslant 0.26$ grams, and the estimated glomerular filtration rate (GFR) had to remain within $10 \%$ of the screening value. These criteria need to be achieved on two consecutive visits and no steroid taper was required. The LUNAR outcome required the serum creatinine level to be within 15\% of the baseline level and the urine protein/creatinine ratio had to be $\leqslant 0.50$ grams. The ACCESS complete response included the stabilization or improvement of the estimated glomerular filtration rate within $25 \%$ of the baseline value and the urine protein to creatinine ratio to be $\leqslant 0.50$ grams. The urinalysis results were not included in the complete response criteria. The ALMS outcome included that the urine protein/creatinine ratio had to be $\leqslant 0.50$ grams and also required normalization of the serum creatinine and urinalysis. The ACR outcome required that the urine creatinine ratio be $\leqslant 0.20$ grams. The estimated glomerular filtration rate (eGFR) had to be within $25 \%$ of the baseline value, and normalization of urinalysis was required. The ACR outcome did not include steroid taper, but the LUNAR, ALMS, and the ACCESS outcome criteria all required that prednisone be successfully tapered to $\leqslant 10 \mathrm{mg} /$ day. 


\section{Cureus}

\begin{tabular}{|l|l|l|l|l|l|}
\hline Criteria & $\begin{array}{l}\text { Urine protein } \\
\text { creatinine ratio }\end{array}$ & $\begin{array}{l}\text { Creatinine or estimated } \\
\text { glomerular filtration rate }\end{array}$ & $\begin{array}{l}\text { Urinalysis, } \\
\text { cells or casts }\end{array}$ & $\begin{array}{l}\text { Steroid } \\
\text { taper } \\
\text { required }\end{array}$ & $\begin{array}{l}\text { Criteria must be met on } \\
\text { two successive visits }\end{array}$ \\
\hline BMS & $\leq 0.26$ & $\begin{array}{l}\text { Within } 10 \% \text { of the screening } \\
\text { or baseline value }\end{array}$ & Normal & No & Yes \\
\hline ACR & $\leq 0.20$ & $\begin{array}{l}\text { Within } 25 \% \text { of the screening } \\
\text { or baseline value }\end{array}$ & Normal & $\begin{array}{l}\text { Not } \\
\text { addressed }\end{array}$ & No \\
\hline LUNAR & $\leq 0.50$ & $\begin{array}{l}\text { Within } 15 \% \text { of the screening } \\
\text { or baseline value }\end{array}$ & Normal & Yes & No \\
\hline ALMS & $\leq 0.50$ & Normal & Normal & Yes & No \\
ACCESS $\leq 0.50$ & $\begin{array}{l}\text { Normal or within } 25 \% \text { of the } \\
\text { baseline value }\end{array}$ & $\begin{array}{l}\text { Not a } \\
\text { component }\end{array}$ & Yes & No \\
\hline
\end{tabular}

\section{TABLE 1: Definition of the complete response in lupus nephritis trials.}

BMS: the Bristol-Myers Squibb, ACR: the American College of Rheumatology, LUNAR: the lupus nephritis assessment with rituximab, ALMS: the Aspreva Lupus Management Study and ACCESS: the Abatacept and Cyclophosphamide Combination Efficacy and Safety Study (reprinted from the abatacept for the lupus nephritis 2012 [10], with permission from Dr. Wofsy, the author).

\section{Statistical methods}

The patients were seen at variable intervals, and if a patient satisfied the response criteria at a given visit, we assume that the response criteria were satisfied sometime between that visit and the previous visit (“interval censoring”). To estimate probabilities of the time, until a response taking into account interval censoring, we estimated the survival function by using the nonparametric method of Wellner and Zhan as implemented in the SAS (SAS Institute Inc, Cary, North Carolina) macro EMICM [11].

\section{Results}

The 20 patients consisted of 18 females and were predominantly the African Americans ( $n=$ nine) and the Caucasian Americans ( $n=$ seven). The ages ranged from 18 to 70 years at the time of starting MMF. The probability of achieving a urine protein/creatinine ratio below 0.50 grams within 180 days was estimated to be 63\% (95\% confidence interval 41\%-84\%).

Table 2 shows the estimated probability of achieving a urine protein/creatinine ratio less than 0.50 grams within six months overall and in subgroups defined by the race and biopsy class. The estimated probability of achieving this goal was substantially lower among the African Americans. 


\section{Cureus}

\begin{tabular}{ll} 
Subgroup & Estimated probab \\
\hline All patients $(n=20)$ & $63 \%(41 \%, 84 \%)$ \\
\hline Race & \\
Caucasian American $(n=7)$ & $100 \%$ \\
African American $(n=9)$ & $40 \%(6 \%, 73 \%)$ \\
Class of lupus nephritis & \\
Class III $(n=8)$ & $72 \%(43 \%, 99 \%)$ \\
Class IV $(n=10)$ & $60 \%(31 \%, 89 \%)$ \\
Class V $(n=6)$ & $50 \%(10 \%, 90 \%)$
\end{tabular}

TABLE 2: The estimated probability of achieving a urine protein/creatinine ratio below 0.5 within 180 days of the treatment initiation, overall and in subgroups.

Table 3 shows the estimated probability of achieving the response from each of the clinical trial sets. The probability of the response at 90 and 180 days was 5\% and 33\% (BMS), 26\% and 57\% (ACR), and 11\% and 28\% (LUNAR, ALMS, ACCESS). The estimate of long-term response was highest using the ACR renal response.

\begin{tabular}{|l|l|l|}
\hline Response definition & $\begin{array}{l}\text { Probability of the response within } \mathbf{9 0} \text { days } \\
\mathbf{( 9 5 \%} \mathbf{C l})\end{array}$ & $\begin{array}{l}\text { Probability of the response within } 180 \text { days } \\
\mathbf{( 9 5 \%} \mathbf{C l})\end{array}$ \\
\hline BMS & $5 \%(1 \%, 15 \%)$ & $33 \%(9 \%, 37 \%)$ \\
\hline ACR & $26 \%(4 \%, 48 \%)$ & $57 \%(35 \%, 79 \%)$ \\
\hline LUNAR/ALMS/ACCESS & $11 \%(1 \%, 25 \%)$ & $28 \%(7 \%, 49 \%)$ \\
\hline
\end{tabular}

TABLE 3: The estimated proportion with remission by 90 and 180 days based on different definitions.

Figure 1 shows the estimate of the probability that the patients would not achieve a urine protein/creatinine ratio below 0.50 grams at various time points after starting MMF. Fifty-two percent of the SLE patients reached 0.50 grams of proteinuria within 51 days of starting MMF (95\% confidence interval 29\%-74\%). Seventy-seven percent reached 0.50 grams or less within 260 days (95\% confidence interval 57\%-97\%). 


\section{Cureus}

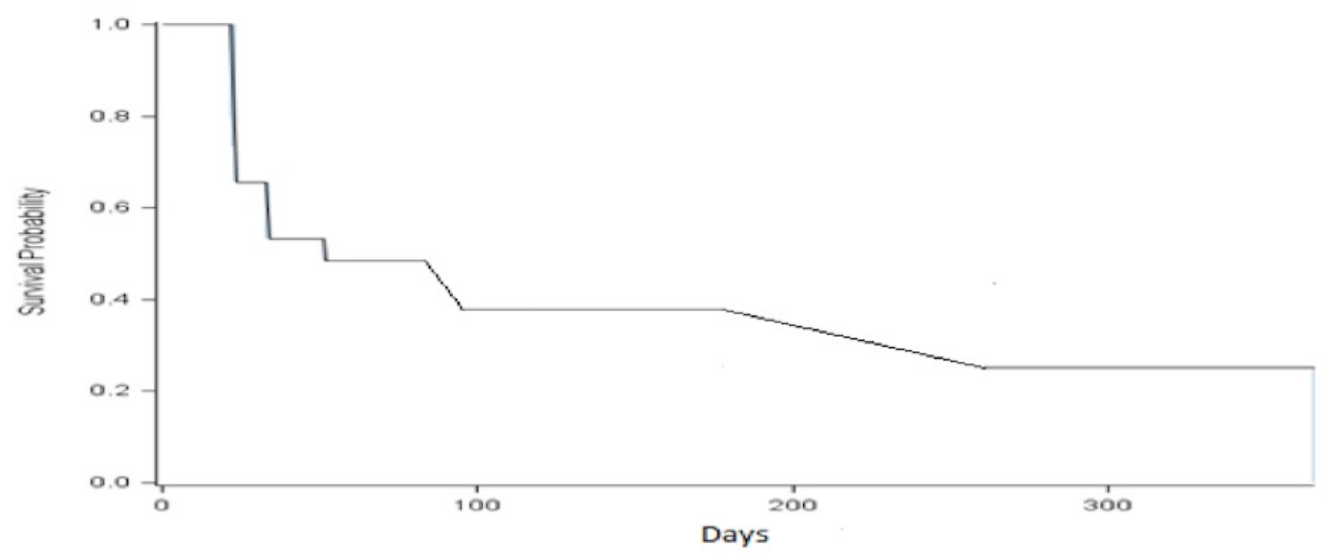

FIGURE 1: The timing (days) of the urinary protein to creatinine ratio reaches at or below 0.5 grams in the lupus nephritis.

\section{Discussion}

We report the outcomes of the treatment with mycophenolate mofetil as first-line therapy in Hopkins Cohort patients with class II, IV, or V lupus nephritis. Our study demonstrates that the majority of the patients in the clinical practice with newly diagnosed lupus nephritis (77\%) can reach a urine protein to creatinine ratio of 0.50 grams or less within nine months after the initiation of mycophenolate mofetil.

The risk of developing the end-stage renal disease is 2.6- to 5.6- fold greater in the African Americans than in the European Americans [6]. We also showed the response in the African American was slower compared to the Caucasian group. This response rate, however, appears to be lower in the African Americans.

The normalization of urine protein is clinically prognostic. An analysis of 90 patients participating in the Euro-Lupus Nephritis Trial revealed that a decrease in proteinuria of $<1$ gm/day at six months predicted the long-term renal outcome for 10 years [12]. Dall'Era, et al. found that a rapid decline in the proteinuria within the first eight weeks of the treatment correlated strongly with achieving the response criteria at 24 weeks [13].

This is the first study to implement and compare the renal outcome measures developed for randomized clinical trials in routine clinical practice. Using response criteria from several recent clinical trials (BMS, ACR, LUNAR, ALMS, and ACCESS), we observed great variability in the response rates. The probability of response at 180 days was 33\% (BMS), and 28\%

(LUNAR/ALMS/ACCESS). Interestingly, the probability of the response at 180 days was higher (57\%) in the ACR response criteria, which could be due to the requirement in the reduction of urine protein creatinine ratio below 0.20 grams.

As we studied a small group of the patients, the validation of our findings should be considered using the long-term renal outcomes.

\section{Conclusions}

The complete renal response with mycophenolate mofetil as the first-line therapy, in the routine clinical practice, was slow and by most indices, reached in only a minority of the patients by the end of six months of induction therapy. This indicates the urgent need for faster 
and more effective lupus nephritis treatments.

\section{Additional Information Disclosures}

Human subjects: Consent was obtained by all participants in this study. John Hopkins IRB issued approval NA-00039294. The Hopkins Lupus Cohort was approved annually by the Johns Hopkins University School of Medicine. The written consent was obtained from all the patients. Animal subjects: All authors have confirmed that this study did not involve animal subjects or tissue. Conflicts of interest: In compliance with the ICMJE uniform disclosure form, all authors declare the following: Payment/services info: I have communicated with all of my coauthors and obtained their full disclosure. The authors declare that they have no competing interests: Homa Timlin, MSc. MRCP: None Laurence S Magder Ph.D. M.P.H: None The study was supported by NIH AR 043727 and 069572 Recipient of both grants: Michelle Petri M.D. M.P.H. Financial relationships: All authors have declared that they have no financial relationships at present or within the previous three years with any organizations that might have an interest in the submitted work. Other relationships: All authors have declared that there are no other relationships or activities that could appear to have influenced the submitted work.

\section{References}

1. Kasitanon N, Magder LS, Petri M: Predictors of survival in systemic lupus erythematosus . Medicine (Baltimore). 2006, 85:147-56.

2. Dooley MA, Aranow C, Ginzler EM: Review of ACR renal criteria in systemic lupus erythematosus. Lupus. 2004, 13:857-60.

3. Alarcón GS, McGwin G Jr, Petri M, et al.: Baseline characteristics of a multiethnic lupus cohort: PROFILE. Lupus. 2002, 11:95-101.

4. Cervera R, Khamashta MA, Font J, et al.: Morbidity and mortality in systemic lupus erythematosus during a 10-year period: A comparison of early and late manifestations in a cohort of 1,000 patients. Medicine. 2003, 82:299-308. 10.1097/01.md.0000091181.93122.55

5. Bastian HM, Roseman JM, McGwin G, et al.: Systemic lupus erythematosus in three ethnic groups. XII. Risk factors for lupus nephritis after diagnosis. Lupus. 2002, 11:152-160.

6. Freedman BI, Langefeld CD, Andringa KK, et al.: End-stage renal disease in African Americans with lupus nephritis is associated with APOL1. Arthritis Rheumatol. 2014, 66:390-6. 10.1002/art.38220

7. Tektonidou MG, Dasgupta A, Ward MM: Risk of end-stage renal disease in patients with lupus nephritis, 1971-2015: a systematic review and Bayesian meta-analysis. Arthritis Rheumatol. 2016, 68:1432-41. 10.1002/art.39594

8. Hoover PJ, Costenbader KH: Insights into the epidemiology and management of lupus nephritis from the US rheumatologist's perspective. Kidney Int. 2016, 90:487-92. 10.1016/j.kint.2016.03.042

9. Dall'Era M, Cisternas MG, Smilek DE, et al.: Predictors of long-term renal outcome in lupus nephritis trials: Lessons learned from the Euro-Lupus Nephritis cohort. Arthritis Rheumatol. 2015, 67:1305-13. 10.1002/art.39026

10. Wofsy D, Hillson JL, Diamond B: Abatacept for lupus nephritis: Alternative definitions of complete response support conflicting conclusions. Arthritis Rheumatol. 2012, 64:3660-5. 10.1002/art.34624

11. Wellner JA, Zhan Y: A hybrid algorithm for computation of the nonparametric maximum likelihood estimator from censored data. J Am Stat Assoc. 1997, 92:945-59. 10.1080/01621459.1997.10474049

12. Houssiau FA, Vasconcelos C, D'Cruz D, et al.: Early response to immunosuppressive therapy predicts good renal outcome in lupus nephritis: Lessons from long-term follow-up of patients in the Euro-Lupus Nephritis Trial. Arthritis Rheumatol. 2004, 50:3934-40. 10.1002/art.20666

13. Dall'Era M, Stone D, Levesque V, et al.: Identification of biomarkers that predict response to treatment of lupus nephritis with mycophenolate mofetil or pulse cyclophosphamide. 


\section{Cureus}

Arthritis Care Res. 2011, 63:351-7. 10.1002/acr.20397 